RESEARCHARTICLE

\title{
Upward, Downward, and Horizontal Social Comparisons: Effects on Adjustment, Emotions, and Persistence in Teachers
}

\author{
Sonia Rahimi, Nathan C. Hall, Hui Wang, and Rebecca Maymon \\ Department of Educational and Counselling Psychology, McGill University, Canada
}

\begin{abstract}
The present study investigated the effects of three types of social comparisons in teachers (downward, horizontal, upward) as moderated by years of teaching experience on burnout, job satisfaction, intentions to quit, discrete teaching-related emotions, and illness symptoms. Findings from a sample of 513 teachers showed downward comparisons with worse-off others to positively predict job satisfaction and anger, and horizontal comparisons with similar peers found to have unanticipated negative effects on all variables assessed. In contrast, upward social comparisons to adaptive role models predicted significantly better levels on each study outcome. The results further showed significant interactions between upward comparisons and teaching experience on job satisfaction, intentions to quit, and enjoyment, with new teachers reporting higher job satisfaction and enjoyment, as well as lower intentions to quit, when they engaged in upward comparisons. Implications for professional development and future research are discussed.
\end{abstract}

\section{Keywords}

\section{G Open Access}

Citation: Rahimi, S., Hall, N.C., Wang, H., Maymon, R. (2017). Upward, Downward, and Horizontal Social Comparisons: Effects on Adjustment, Emotions, and Persistence in Teachers. Interdisciplinary Education and Psychology, 1(1):10.

Received: July 28, 2017

Accepted: November 16, 2017

Published: November 28, 2017

Copyright: @ 2017 Rahimi et al. This is an open access article distributed under the terms of the Creative Commons Attribution License, which permits unrestricted use, distribution, and reproduction in any medium, provided the original author and source are credited.

\section{Corresponding author:}

Sonia Rahimi, Department of Educational and Counselling Psychology, McGill University, Montreal, QC, Canada E-mail: sonia.rahimi@mail.mcgill.ca
Social comparisons, teachers, burnout, persistence, emotions

\section{Introduction}

Recent statistics suggest that teacher motivation, burnout, and attrition have become problematic, with substantial proportions of teachers leaving the occupation within the first five years (e.g., Norway, 40\%, Roness, 2011; U.S., 46\%, Ingersoll, 2003; U.K., 40\%, Kyriacou \& Kunc, 2007; Canada, 20-40\%, Fédération canadienne des enseignantes et des enseignants, 2004; Houlfort \& Sauvé, 2010; Karsenti \& Collin, 2013; Australia, 30\%, Watt \& Richardson, 2007). Varied explanations for the rapid departure of teachers from the workplace have been examined ranging from structural contributors (e.g., school administration; McCormick \& Shi, 1999; government policies; McCormick, 1997) to demographic variables (e.g., gender, Greenglass \& Burke, 1988; age, Friedman \& Farber, 1992). Contextual variables such as time constraints, lack of administrative support, student misbehaviour and low achievement, and heavy workloads have also received increasing research attention (Antoniou, Polychroni \& Vlachakis, 2006; Blase, 1986; Karsenti \& Collin, 2013; Manassero et al., 2006), with studies showing accumulated stress and burnout from these sources to contribute to a teacher's decision to leave the profession (Yong \& Yue, 2007; Zhang, \& Zhu, 2007).

Concerning research on factors that may help protect teachers from the deleterious effects of teaching-related stress, psychology research suggests that individual differences in personality characteristics (e.g., conscientiousness; Kokkinos, 2007), motivational beliefs (e.g., goals: Butler, 2007; self-efficacy: Wang, Hall, \& Rahimi, 2015; causal attributions: Manassero et al., 2006), or coping strategies (e.g., Austin, Shah, \& Muncer, 2005; Griffith, Steptoe, \& Cropley, 1999) can help to explain vulnerability to stress in teachers. Research on psychological variables in teachers further suggests that teachers' cognitions concerning their social environment may also influence not only their emotions in class (e.g., anger, 
enjoyment; Frenzel, Goetz, Stephens, \& Jacob, 2009) but also their self-reported burnout levels (e.g., depersonalization; Byrne, 1994). However, empirical research on how teachers' beliefs concerning their social environment help them cope with the demands and challenges of their profession are currently lacking (e.g., Sutton, 2004). Moreover, despite a substantial body of research illustrating the potential benefits of strategic social comparisons with one's peers in stressful environments (e.g., Suls, Martin, \& Wheeler, 2002; Suls \& Wheeler, 2000), specific research on the potential benefits of teachers' beliefs concerning other teachers has yet to be conducted.

\section{Social Comparisons}

In contrast to psychological constructs previously examined in research with teachers that have mainly involved persistent motivational beliefs or personality characteristics, motivational strategies (also referred to as "coping strategies" in highly stressful circumstances; Skinner, Edge, Altman, \& Sherwood, 2003, or emotional regulation, Gross, 1998) represent how individuals intentionally respond to situational challenges and are thus more dynamic or reflexive in nature. Coping is understood as cognitive or behavioral responses to manage significant stressors (Lazarus \& Folkman, 1984), with one specific class of coping strategies involving adaptively comparing oneself with others so as to protect or foster psychological well-being (Suls et al., 2002). These strategies have consistently been found to promote adjustment in response to varied developmental challenges across the life span, as illustrated in empirical research following from both social and developmental psychological traditions.

\section{Social comparison processes}

As a prominent theory of motivational self-regulation bridging psychological literatures, Heckhausen, Wrosch, and Schulz's (2010) Motivational Theory of Life-Span Development attempts to explain how individuals regulate their motivation in response to situational opportunities and constraints through three main types of motivational strategies (Hall, Chipperfield, Heckhausen, \& Perry, 2010). In educational settings, the most beneficial strategies typically involve goal engagement (effort, help-seeking, reducing distractions) and the most detrimental strategies tend to reflect goal disengagement (lowering expectations; e.g., teachers' intentions to quit; Klassen \& Chiu, 2011). Further, self-protective strategies involving the cognitive reinterpretation of setbacks to preserve psychological resources have shown considerable promise for fostering personal and academic development in students (e.g., Hall, 2008; Hall, Chipperfield, Perry, Ruthig, \& Goetz, 2006; Hall, Perry, Ruthig, Hladkyj, \& Chipperfield, 2006) and teachers (e.g., Totterdell \& Parkinson, 1999). Nevertheless, existing research on self-protective strategies in educational populations has focused primarily on one strategy, namely positive reappraisal (i.e., "finding the silver lining"), leaving other potentially beneficial self-protective strategies unexplored. More specifically, whereas research informed by Heckhausen et al.'s (2010) model has examined the benefits of strategic comparisons with others on well-being in adult populations (e.g., elderly adults; Chipperfield \& Perry 2006; Hall et al., 2010; Heckhausen, 1999), no studies to date have explored the potential emotional and motivation benefits of this type of motivational strategy for teachers.

Social-psychological research on cognitions, emotions, and self-theories has for decades examined how people make social comparisons and the effects thereof (Suls \& Wheeler, 2000). As an essential component of human socialization, comparing oneself with others is typically an adaptive process involving both an active search for self-relevant information about others, as well as selective affiliation (Buunk \& Mussweiler, 2001; Taylor \& Lobel, 1989). According to Festinger (1954), individuals seek out information about others primarily to facilitate accurate self-evaluation (Suls et al., 2002; Taylor \& Lobel, 1989), with the resulting contrasts leading to specific psychological and behavioral consequences (e.g., affect: Smith, 2000; White, Langer, Yariv, \& Welch, 2006; motivation: Bailis, Chipperfield, \& Perry, 2005; achievement, Blanton, Buunk, Gibbons, \& Kuyper, 1999). Nevertheless, research in this domain also highlights the importance of individual differences and demographic factors in social comparisons processes (e.g., achievement goal orientation, Butler, 1992; emotions, Lyubomirsky, \& Ross, 1997; self-construal, Stapel \& Koomen, 2001; employment status, Sheeran, Abrams, \& Orbell, 1995). 


\section{Downward social comparisons}

Commonly defined as comparing oneself with worse-off others, the motivation behind downward social comparisons is assumed to be self-enhancement of subjective well-being and self-esteem (Hakmiller, 1966; Taylor \& Lobel, 1989; Wills, 1981). The psychological benefits of downward comparisons are supported by research showing this strategy to be more beneficial for overall adjustment and mood than upward or horizontal comparisons (Locke, 2003), with individuals often engaging in downward comparisons when they feel threatened or perceive a lack of personal control (Stewart, Chipperfield, Ruthig, \& Heckhausen, 2013; Pyszcynski, Greenberg, \& Laprelle, 1985; Wheeler \& Miyake, 1992; Wills, 1981). Although some studies suggest downward comparisons can negatively affect selfevaluations and emotions under stressful circumstances (Buunk, Collins, Taylor, VanYperen, \& Dakof, 1990; Kemmelmeier \& Oyserman, 2001), other findings show downward comparisons to help maintain positive self-perceptions and emotional well-being (Bailis \& Chipperfield, 2006; Lockwood, Dolderman, Sadler, \& Gerchak, 2004), particularly in lowcontrol circumstances (e.g., older adulthood; Bailis et al, 2005; Heckhausen \& Schulz, 1995). As such, empirical findings to date on the psychological benefits of downward comparisons are mixed and have yet to be investigated in teachers.

\section{Horizontal social comparisons}

In the present study, horizontal comparisons are conceptualized as perceived similarity with one's peers for the purpose of self-enhancement and emotional well-being. Following from related social-psychological traditions concerning need for affiliation (Murray, 1938), social support (Cohen \& McKay, 1984), Self-Determination Theory (relatedness; Ryan \& Deci, 2000), and Attachment Theory (Bowlby, 1951, 2008), findings consistently demonstrate the importance of perceived belongingness and closeness with similar others (for reviews, see Bergin \& Bergin, 2009; Niemiec \& Ryan, 2009). In educational settings, findings further show students who perceive closeness, relatedness, and support from peers to demonstrate better psychological, behavioral, and academic outcomes (e.g., Freeman, Anderman, \& Jensen, 2007; Furrer \& Skinner, 2003; Goodenow, 1993; Locke, 2003; Van Ryzin, Gravely, \& Roseth, 2009). However, although related constructs such as collective self-esteem have also been found to predict better psychological adjustment in adult populations (e.g., Bailis, Chipperfield, \& Helgason, 2008; Crocker, Luhtanen, Blaine, \& Broadmax, 1994), the extent to which teachers strategically compare themselves with similar others in response to teachingrelated challenges has yet to be examined.

\section{Upward social comparisons}

Social comparison theories posit that people are often motivated to seek out positive characteristics they share with more successful others so as to utilize positive role models to inspire accomplishments (Lockwood, Jordan, \& Kunda, 2002). The term "role model" is defined as an individual with whom one compares oneself who has achieved a desired goal or status (Holton, 2004) and inspires one to improve one's own requisite competencies (a selfimproving motive, Festinger, 1954; Wood, 1989; see also Lockwood et al., 2002). Accordingly, although some negative effects of this comparison strategy have been reported (e.g., Bailis \& Chipperfield, 2006; Buunk et al., 1990; Jagacinski \& Nicholls, 1987), upward comparisons have typically been found to foster psychological adjustment across interpersonal, achievement, and health domains (for reviews, see Bailis et al., 2005; Buunk et al., 1990; Collins, 1996; Corcoran, Crusis, \& Mussweiler, 2011; Festinger, 1954; Tesser, 1988; Taylor \& Lobel, 1989). In educational settings specifically, although comparisons with better-off others have been shown to promote student motivation (e.g., Huguet, Dumas, Monteil, \& Genestoux, 2001; Lockwood \& Kunda, 1997), the potential psychological benefits of this social comparison strategy for teachers has not been empirically explored.

\section{Social comparisons in teachers}

When dealing with instructional challenges, such as student misbehaviour or poor performance, teachers are likely to compare themselves with other teachers that, in many cases, should prove useful for motivating themselves as well as regulating their negative emotions. However, in contrast to existing research examining the effects of social comparisons on adjustment and achievement among adults in interpersonal contexts (e.g., romantic relationships) and health domains (e.g., serious illness), and students in K-12 settings (e.g., achievement outcomes), notably little research to date has examined effects on 
well-being and motivation in teachers. Concerning existing research with teachers on constructs related to social comparisons, studies have found higher levels of collective selfefficacy, defined as the perceived confidence of an individual teacher in the collective capabilities of teachers as a group (e.g., Tschannen-Moran, Hoy, \& Hoy, 1998), to correspond with greater student learning (Parker, Hannah, \& Topping, 2006) and lower levels of burnout (Skaalvik \& Skaalvik, 2007). Similarly, not unlike the observed emotional benefits of teachers' social goals reflecting a desire to connect emotionally with students (e.g., Butler, 2012; Butler \& Shibaz, 2008), teachers who perceive a sense of relatedness to other teachers also report higher levels of instructional engagement and lower negative emotions (Klassen, Perry, \& Frenzel, 2012). In addition, teachers are more likely to engage in upward comparisons with individuals whom they perceive as having attained desired achievable goals (Smith, 2000), or to individuals that inspire them (Kitchel et al., 2012). However, this research on general social perceptions in teachers is mixed, with findings also showing perceived relatedness with colleagues to negatively predict work engagement and enjoyment (Klassen et al., 2012), with the findings also limited in that they do not differentiate between social comparison types (downward, horizontal, upward).

\section{The Present Study}

Whereas research to date exploring teacher motivation and emotions is consistent with a traditional expectancy-value perspective on achievement motivation (Klassen, Tze, Betts, \& Gordon, 2011; Wigfield, Tonks, \& Klauda, 2009), research exploring the role of higher-order self-regulation strategies is presently lacking, particularly concerning social comparisons. Given studies underscoring the importance of motivational strategies and volition in educational settings (e.g., Kuhl, 1996; Oettingen \& Gollwitzer, 2009; Pintrich, 1999; Wolters, 2003) higher-order, self-regulatory strategies should similarly predict psychological outcomes in teachers. The present study aimed to address this research gap in investigating the effects of specific types of social comparisons (downward, horizontal, upward) on burnout, job satisfaction, intentions to quit, emotions and illness symptoms in teachers.

\section{Hypothesis 1: Downward comparisons}

Downward social comparisons should be valuable for teachers in predicting better adjustment and emotional outcomes (e.g., well-being, Locke, 2003; Lockwood \& Kunda, 1997). To the extent that the teaching profession is increasingly characterized by stressors beyond the personal control of teachers (e.g., workload, administrative support), the effects of downward comparisons were expected to be consistent with findings showing comparisons with worse-off others to benefit individuals in low-control circumstances (e.g., Bailis et al, 2005; Heckhausen \& Schulz, 1995).

\section{Hypothesis 2: Horizontal comparisons}

Horizontal social comparisons were similarly expected to be psychologically beneficial for teachers as observed in previous studies consistently highlighting the benefits of associated constructs such as relatedness (e.g., Ryan \& Deci, 2000), belongingness (e.g., Van Ryzin et al., 2009), and collective self-efficacy (e.g., Goddard, Hoy, \& Hoy, 2000). Whereas findings concerning the effects of perceived relatedness on teachers' adjustment are mixed (e.g., relatedness; Klassen et al., 2012), the present hypothesis nonetheless aligns with related research with teachers on the psychological benefits of other comparable constructs, namely collective self-efficacy (e.g., Skaalvik \& Skaalvik, 2007; see also Parker et al., 2006; Tschannen-Moran et al., 1998).

\section{Hypothesis 3: Upward comparisons}

Upward social comparisons were anticipated to promote better adjustment outcomes and emotions in teachers following from findings with adult populations showing motivational and emotional benefits from contrasts with better-off others (e.g., Huguet et al., 2001; Lockwood \& Kunda, 1997). Whereas the psychological and health effects of upward comparisons in prior research is mixed (e.g., Bailis \& Chipperfield, 2006; Buunk et al., 1990; Jagacinski \& Nicholls, 1987), this strategy was expected to be beneficial for teachers given the present operationalization of upward contrasts as involving role models representing attainable teaching goals (as opposed to simply more successful others, possibly resulting in envy or resentment). 


\section{Hypothesis 4: Moderation by experience}

Finally, it was expected that the psychological effects of each type of social comparison would be moderated by teachers' years of experience, with new teachers benefitting more from social comparisons than more experienced teachers. This hypothesis is consistent with prior studies showing social comparison effects to be moderated by individual differences (e.g., perceived control, Buunk et al., 1990) and studies based on Heckhausen et al.'s (2010) theory showing beliefs concerning others to have stronger effects for individuals facing control-limiting health challenges (e.g., collective self-efficacy, Bailis \& Chipperfield, 2006; downward comparisons, Stewart, Chipperfield, Perry, \& Weiner, 2012; for a review, see Heckhausen \& Schulz, 1995) or reporting low perceptions of control (e.g., upward comparisons, Bailis \& Chipperfield, 2006). To the extent that new teachers experience threatened perceptions of control concerning the profession (e.g., Roth \& Gold, 2003) and are logically more likely to engage in certain comparisons (e.g., upward, or senior colleagues), they were expected to experience greater motivational and emotional benefits than their more experienced counterparts. Nevertheless, this interaction hypothesis should be considered speculative in nature given a lack of existing research on the moderating effects of experience or perceived control on the well-being effects of motivational variables for teachers.

\section{Method}

\section{Participants and procedure}

Practicing teachers $(N=513)$ were recruited from two Canadian provinces via mass emails from school principals and teaching union representatives at the beginning of the winter academic semester. This project was approved by and conducted according to the standards of the McGill Research Ethics Board (REB). In the web-based questionnaire, participants were first asked to complete demographic items (e.g., age, gender, etc.) followed by our selfreported study measures. The mean age of the participants was 41.26 years $(S D=9.67$; range: $23-68$ years), $85.2 \%$ were female, and the mean number of years employed in the teaching profession was 12.90 years $(S D=8.64$; range: $0-45)$. The sample consisted of primary (grades 1-6; 51.8\%, $n=251$ ), secondary (grades $7-11 / 12 ; 42.3 \%, n=205$ ), and junior college teachers (grades 12-13; 6\%, $n=29$ ). Most participants held a bachelor's degree $(72.8 \%)$ or master's degree $(24.6 \%)$, with the ethnic composition including primarily Caucasian (90.6\%) participants, (Caribbean, 2.3\%; East Asian, 1.9\%; South Asian, 1.7\%; African, 1.7\%; WestAsian, .8\%; Aboriginal, .6\%; SoutheastAsian, .4\%).

\section{Study measures}

Descriptive statistics for each study measure including means, standard deviations, ranges, and internal reliabilities are provided in Table 1 below.

\section{Social comparisons}

Three multi-item measures adapted from the Optimization of Primary and Secondary Control Scale by Heckhausen and colleagues (OPS; see Haase, Heckhausen, \& Koeller, 2008; Heckhausen, Schults, \& Wrosch, 1998; 1 = strongly disagree to 5 = strongly agree) were developed for this study to evaluate downward, horizontal, and upward social comparisons in teachers, with two items measuring intentional interpersonal contrasts with respect to downward comparisons $(M=3.03, S D=1.00, r(457)=.51, p<.001$; e.g., "When I experience teaching setbacks, I remind myself that I am better-off than other teachers in many ways"), two items measuring horizontal comparisons $(M=3.34, S D=.89, r(465)=.33, p<.001$; e.g., "When I have difficulties with my students, I keep in mind that other teachers are struggling too"), and two items measuring upward comparisons $(M=3.68, S D=.93, r(457)=.63, p<$ .001; e.g., "When I experience teaching difficulties, I remind myself of successful teachers who overcame similar setbacks").

\section{Burnout}

A modified version of the 22-item, 6-point Maslach Burnout Inventory (MBI; Maslach et al., 1986; 0 = never to 6 = every day), was used to assess burnout. The scale was adapted to refer to "students" as opposed to "recipients," and evaluated emotional exhaustion (nine items; $M=$ 2.47, $S D=1.27, \alpha=.92$; e.g., "I feel emotionally drained from my work"), personal accomplishment (eight items; $M=4.83, S D=.74, \alpha=.75$; e.g., "I can easily understand how my students feel about things"), and depersonalization (five items; $M=.97, S D=.94, \alpha=.71$; 
Table 1. Descriptive statistics for continuous study variables

\begin{tabular}{lcccccc}
\hline \multicolumn{1}{c}{ Variable } & $\alpha / r$ & $M$ & $S D$ & $n$ & Items & Actual range \\
\hline Age & N/A & 41.26 & 9.67 & 469 & 1 & $23-68$ \\
Years of experience & N/A & 12.90 & 8.64 & 487 & 1 & $0-45$ \\
\hline \multirow{2}{*}{ Downward social comparisons } & .51 & 3.03 & 1.00 & 457 & 2 & $1-5$ \\
Horizontal social comparisons & .33 & 3.34 & 0.89 & 465 & 2 & $1-5$ \\
Upward social comparisons & .63 & 3.68 & 0.93 & 457 & 2 & $1-5$ \\
\hline \multirow{3}{*}{ Independent } & measures & & \\
MBI: Emotional exhaustion & .92 & 2.47 & 1.27 & 468 & 9 & $0.11-5.89$ \\
MBI: Personal accomplishment & .75 & 4.83 & 0.74 & 468 & 8 & $2.00-6.00$ \\
MBI: Depersonalization & .71 & 0.97 & 0.94 & 468 & 5 & $0.00-4.80$ \\
Job satisfaction & .90 & 5.07 & 1.38 & 473 & 5 & $1-7$ \\
Intention to quit & .88 & 1.76 & 0.97 & 458 & 3 & $1-5$ \\
Enjoyment & .77 & 3.49 & 0.49 & 454 & 4 & $1.50-4.00$ \\
Anger & .76 & 1.42 & 0.55 & 454 & 4 & $1.00-3.25$ \\
Anxiety & .77 & 1.71 & 0.65 & 454 & 4 & $1.00-3.75$ \\
Illness symptoms & .82 & 2.03 & 0.72 & 468 & 8 & $1-5$ \\
\hline
\end{tabular}

Note. $\mathrm{MBI}=$ Maslach Burnout Inventory.

e.g., "I feel students blame me for some of their problems"). The reliabilities for each subscale were comparable to those in existing published research (e.g., Beckstead, 2002; as $=.90, .79, .71$, respectively).

\section{Job satisfaction}

A 5-item, 7-point measure was used to assess job satisfaction (Moe, Pazzaglia, \& Ronconi, 2010; 1 = strongly disagree to 7 = strongly agree). Sample items included "In most ways my job is close to my ideal" and "If I could live my life over, I would not change the choices made in my job" $(M=5.07, S D=1.38, \alpha=.90$; cf. Moe et al., 2010, $\alpha=.84)$.

\section{Intention to quit}

A3-item, 5-point scale was used to assess teachers' quitting intentions (Hackett, Lapierre, \& Hausdorf, 2001; Occupational Commitment Scale; 1 = very unlikely to $5=$ certain). Sample items included "I intend to move into another profession/occupation" and "I think about quitting the teaching profession" ( $M=1.76, S D=.97, \alpha=.88$; cf. $\alpha=.82$ in Hackett et al., 2001).

\section{Teacher emotions}

A 12-item, 4-pointTeacher Emotions Scale (TES, Frenzel et al., 2009; 1 = strongly disagree to 4 = strongly agree) was used to assess teachers' emotions concerning instructional activities, investigating both emotions related to the teaching process and ongoing activities (enjoyment, anxiety) as well as more specific emotions in response to teaching outcomes (anger). The three subscales measured enjoyment (four items; $M=3.49, S D=.49, \alpha=.77$; e.g., "I generally enjoy teaching"), anger (four items; $M=1.43, S D=.51$, $\alpha=.76$; e.g., "I often feel annoyed while teaching"), and anxiety (four items; $M=1.71, S D=.65$, $\alpha=.77$; e.g., "I feel uneasy when I think about teaching"). Whereas the reliability levels observed were lower than in previous published studies (e.g., Frenzel et al., 2009; as =.92, .89, .86, respectively), they are nonetheless indicative of sufficient internal reliability for analysis $(\alpha \sim .80$; George \& Mallery, 2003) and represent the initial assessment of these measures in a Canadian sample (Klassen et al., 2012).

\section{IIIness symptoms}

A 3-item, 5-point scale was adapted from Cohen and Hoberman (1983; $1=$ not at all in a week to 5 = five or more times $a$ week) to assess teachers' perceived frequency of illness 
symptoms, including headaches, sleep problems, muscle tension, stomach pain, heart pounding, and poor appetite $(M=2.03, S D=.72, \alpha=.82$, cf. Hall et al., $2006, \alpha=.80)$.

\section{Results}

\section{Preliminary analyses}

Independent-samples t-tests were conducted to examine potential initial differences in our study measures as a function of gender. The results showed a weak gender effect such that female teachers $(M=.92, S D=.90)$ reported higher depersonalization than male teachers $(M$ $=1.29, S D=1.13 ; \mathrm{t}(77.61)=2.53, p=.013, d=.25)$. Zero-order correlations (see Table 2) additionally showed positive correlations between each type of social comparison (downward, horizontal, and upward), and an expected pattern of positive relations among similarly valenced dependent measures (e.g., job satisfaction, enjoyment) as well as negative relations between oppositely valenced outcomes (e.g., job satisfaction, exhaustion). Moreover, age was negatively correlated with horizontal comparisons, depersonalization, anger, and anxiety, as well as positively correlated with enjoyment and years of experience. Grade level was positively correlated with depersonalization and negatively correlated with personal accomplishment, warranting the inclusion of both variables as covariates in the main analyses. Finally, although education level was not correlated with any outcome measure, it was confounded with level of instruction and similarly included as a covariate consistent with previous literature (e.g., Kokkinos, 2007; Pas, Bradshaw, \& Hershfledt, 2012).

\section{Main analysis}

Hierarchical linear regressions evaluated the effects of social comparisons on burnout (exhaustion, depersonalization, accomplishment), job satisfaction, quitting intentions, teaching-related emotions (enjoyment, anger, anxiety), and illness symptoms, and the moderating effects of teaching experience. Step 1 included demographic variables evaluated as covariates including teachers' gender, age, highest level of education achieved (postsecondary diploma, bachelor's degree, master's degree, doctoral degree), and grade level of instruction (primary/elementary, secondary/high school, post-secondary). Step 2 evaluated the main effects for each social comparison measure (Hypotheses 1-3) as well as years of experience. Finally, Step 3 assessed the interactions between each social comparison measure and years of experience (Hypothesis 4). All main and interaction effects were meancentered prior to analysis with simple slopes analyses evaluated at one standard deviation above or below the sample mean (Meyers, Gamst, \& Guarino, 2006).

\section{Main effects}

As outlined in Table 3, results showed that whereas downward comparisons predicted higher levels of job satisfaction in teachers, they also predicted higher levels of anger. In contrast, horizontal comparisons predicted higher levels of burnout with respect to emotional exhaustion and depersonalization, as well as lower levels of personal accomplishment. Additionally, horizontal comparisons predicted lower job satisfaction, stronger quitting intentions, lower enjoyment, as well as higher levels of anger, anxiety, and illness symptoms. Finally, upward comparisons were found to predict better levels on each outcome assessed including emotional exhaustion, depersonalization, personal accomplishment, job satisfaction, intentions to quit, enjoyment, anger, anxiety, and illness symptoms.

\section{Interaction effects}

Concerning the hypothesized moderation effects, significant interactions were observed suggesting that the effects of upward social comparisons on job satisfaction (Figure 1), quitting intentions (Figure 2), and enjoyment (Figure 3 ) to vary as a function of years of experience. As illustrated by simple slopes analyses, upward comparisons more significantly predicted greater job satisfaction for teachers with fewer years of experience $(\beta=.35$, $t(377)=4.79, p<.001, \mathrm{Cl}=[.312, .747])$ than more experienced teachers $(\beta=.16, t(377)=2.41$, $p=.016, \mathrm{Cl}=[.044, .428])$. Upward comparisons were also found to more significantly predict higher levels of enjoyment for newer teachers $(\beta=.35, t(373)=4.74, p<.001, \mathrm{Cl}=[.110, .267])$ relative to experienced teachers $(\beta=.16, t(373)=2.46, p=.014, \mathrm{Cl}=[.017, .156])$, with more significant benefits of upward comparisons also found on intentions to quit for new teachers ( $\beta$ $=-.32, t(377)=-4.18, p<.001, \mathrm{Cl}=[-.503,-.181])$ as compared to more experienced teachers $(\beta=-.13, t(377)=-1.94, p=.053, \mathrm{Cl}=[-.282, .002])$. 
Table 2. Zero-order correlations among study variables

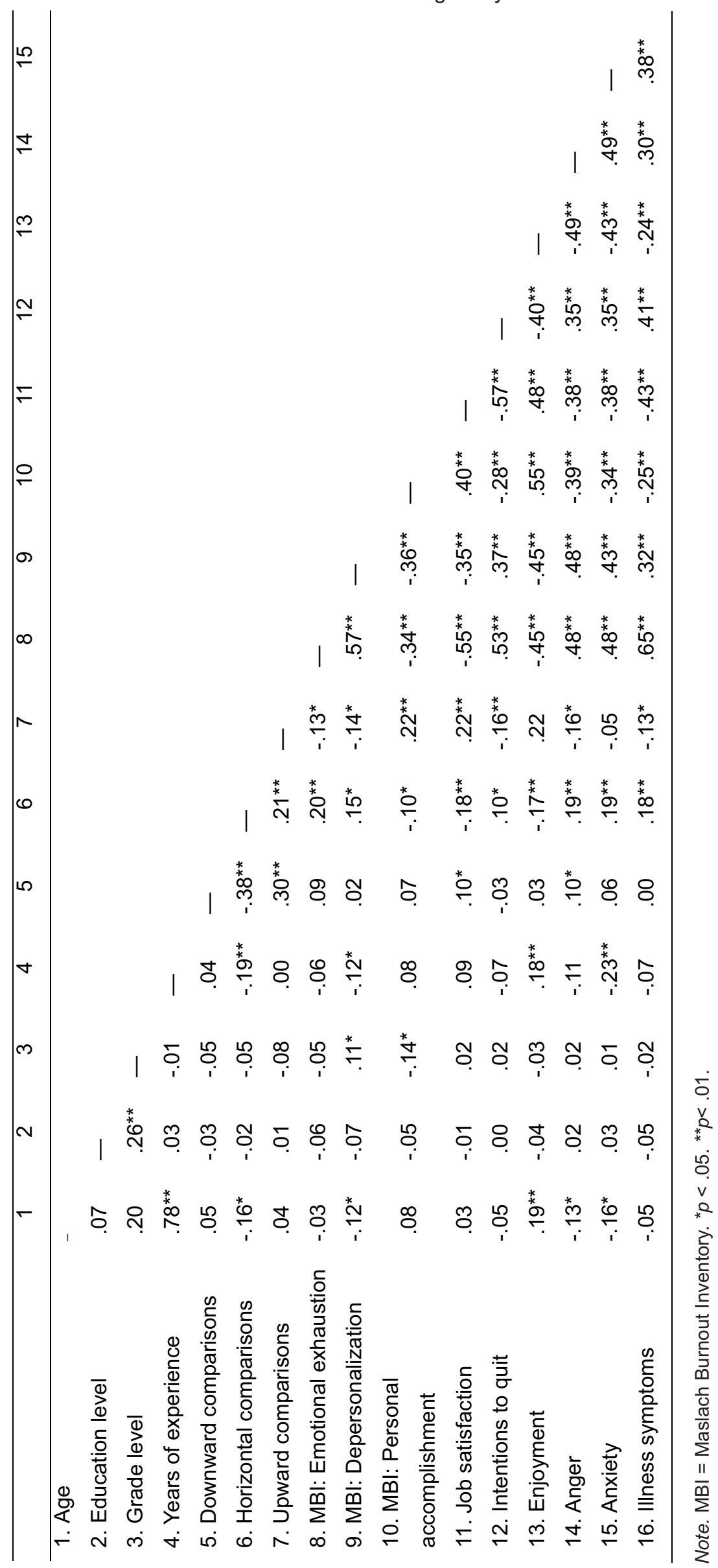




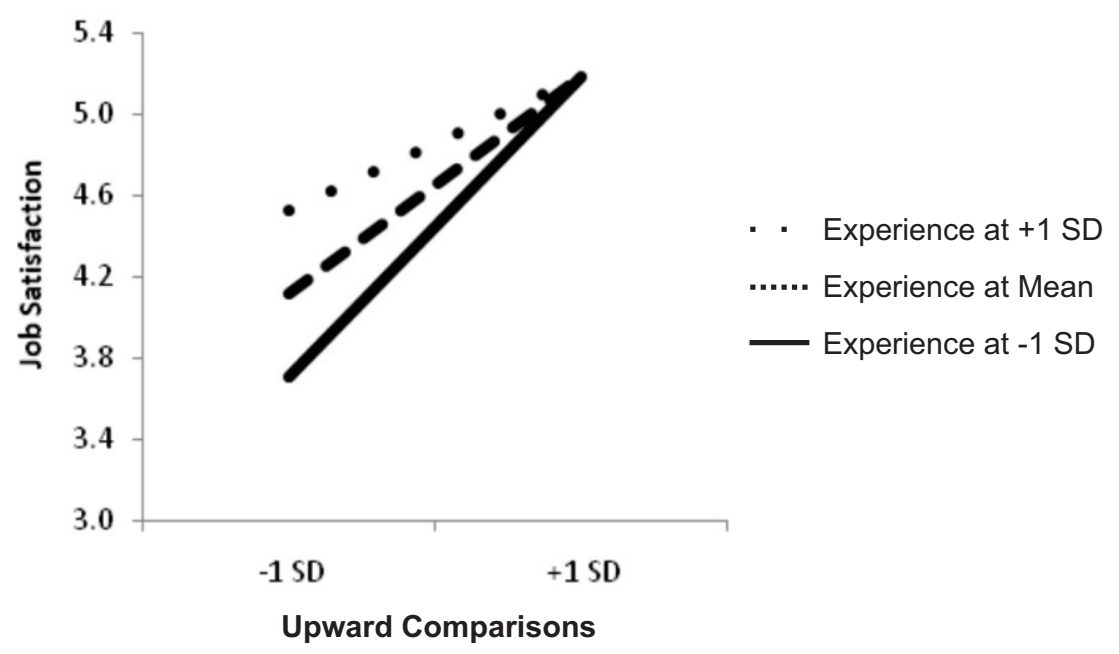

Figure 1. Upward comparisons predicting job satisfaction as a function of years of experience

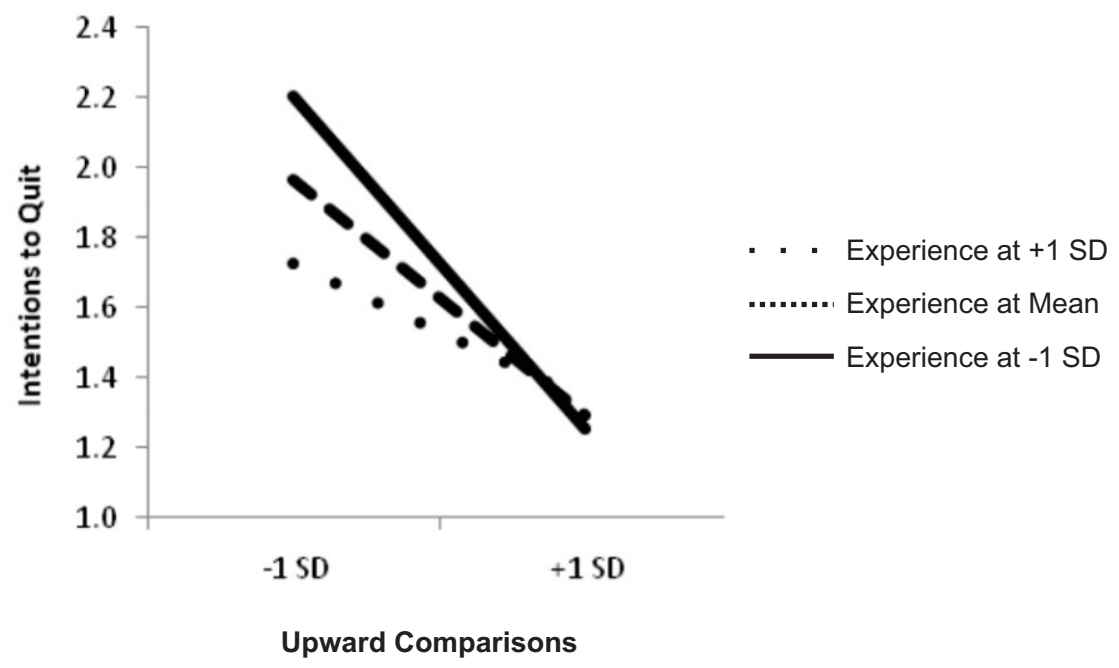

Figure 2. Upward comparisons predicting intentions to quit as a function of years of experience

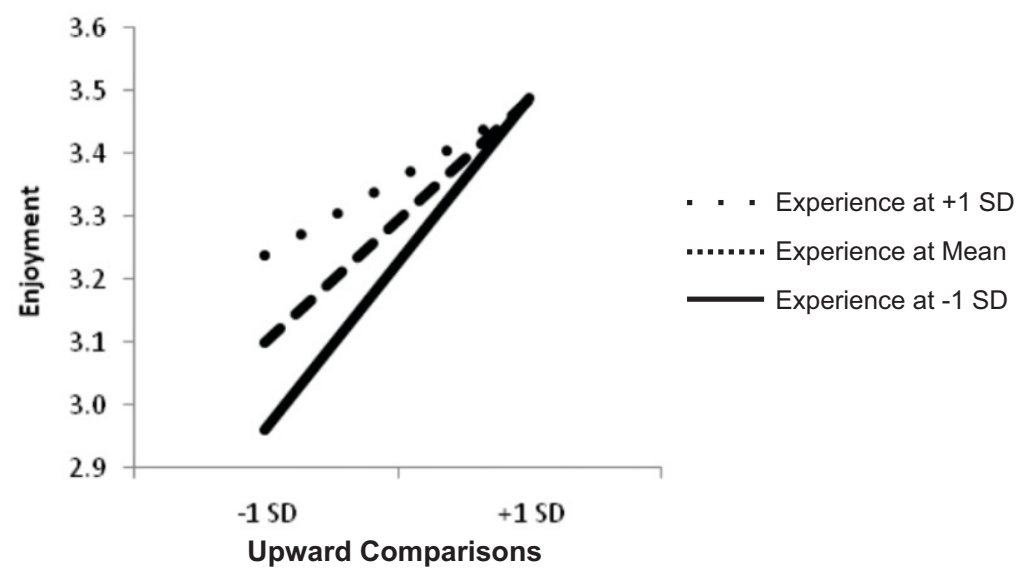

Figure 3. Upward comparisons predicting enjoyment as a function of years of experience 
Table 3. Hierarchical multiple regression analyses

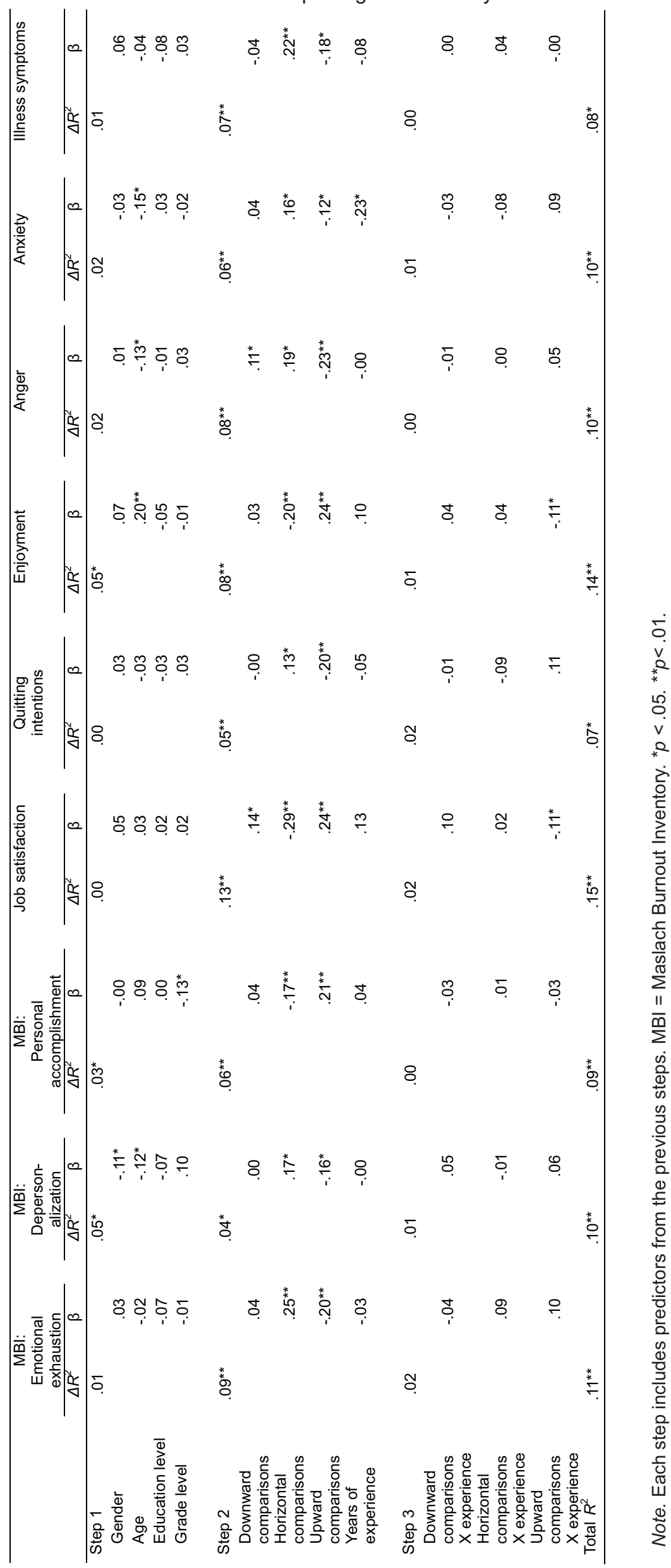




\section{Discussion}

Despite long-standing empirical evidence showing social comparisons to be an effective strategy for coping with stressors in interpersonal, health, and educational settings (e.g., Buunk et al., 1990; Collins, 1996; Corcoran et al., 2011; Festinger, 1954), and related psychosocial variables showing significant benefits for teachers (e.g., relatedness, collective self-efficacy; Klassen et al., 2012, Goddard et al. 2000), social comparisons have not previously been explored as a motivational strategy among teachers. To address this research gap, the present study investigated the psychological effects of social comparisons as a motivational self-regulation strategy among teachers on critical occupational measures of burnout, job satisfaction, and intentions to quit, as well as teaching-related emotions and illness symptoms. Overall, the consistent pattern of results observed provide empirical support for further exploring social comparisons in this population in showing teachers' efforts to compare themselves with other teachers to have both beneficial and detrimental effects depending on the type of comparison made, with these effects being further moderated by teaching experience.

\section{Hypothesis 1: Downward comparisons}

The first study hypothesis proposed that despite mixed findings in other domains on the psychological effects of downward comparisons, teachers who compared themselves to worse-off others should report better adjustment and motivation levels. The present results provide partial support for this hypothesis in showing ambivalent effects of this type of social comparison strategy. Whereas teachers who more frequently compared themselves with worse-off teachers reported greater job satisfaction, they also reported significantly higher levels of anger. As such, these findings are consistent with studies showing downward comparisons to both contribute to better adjustment (e.g., Locke, 2003; Pohlmann, \& Möller, 2009) as well as to more negative emotions toward others (e.g., Buunk et al., 1990). However, given that the mixed effects for downward comparisons were notably weak in magnitude $(\beta s=$ $.11, .14)$, and that no significant effects of this strategy were found for any other measures, the primary implication from these results is that downward comparisons appear to be a largely ineffective predictor of psychological well-being in teachers.

\section{Hypothesis 2: Horizontal comparisons}

As outlined in the second study hypothesis, horizontal social comparisons were similarly expected to predict better well-being outcomes, based in part on previous work showing related socially-oriented variables to predict lower levels of burnout and higher job satisfaction in teachers (e.g., perceived relatedness, collective self-efficacy; Bailis \& Chipperfield, 2006; Klassen et al., 2012; Skaalvik \& Skaalvik, 2007). However, a pattern of results directly opposite of Hypothesis 2 was observed, with comparisons made by teachers to similar others (i.e., other teachers who were similarly struggling to achieve their instructional goals) proving particularly maladaptive for teachers in predicting poorer levels on all outcomes assessed. More specifically, horizontal comparisons predicted not only poorer levels on each burnout measure (emotional exhaustion, depersonalization, personal accomplishment), but also lower job satisfaction, stronger intentions to quit, a more negative profile of teaching-related emotions (lower enjoyment, higher anger and anxiety), and higher levels of reported illness symptoms.

Despite these results being directly contrary to existing research on similar constructs (e.g., positive effects of teacher relatedness on job satisfaction; Skaalvik \& Skaalvik, 2007), they are nonetheless consistent with findings showing teachers who report higher levels of relatedness with colleagues to also experience lower work engagement and enjoyment (Klassen et al., 2012). According to Klassen et al. (2012), teachers' efforts to compare themselves with other teachers who they perceive as similarly unsuccessful should not be equated with efforts to build relationships in the classroom (e.g., social goals, Butler \&Shibaz, 2008), with social comparison research further showing perceptions of similarity with others on undesirable traits can to lead to negative emotions and feelings of insecurity (Locke, 2005). As the present measure of horizontal comparisons included statements such as "If I don't reach my teaching goals, I will tell myself that many other teachers are in the same situation," it is possible that the clearly failure-oriented, commiserative nature of this scale may have contributed to this negative pattern of results (i.e., representing the opposite of collective selfefficacy). 


\section{Hypothesis 3: Upward comparisons}

The third hypothesis proposed that upward social comparisons would be beneficial for teachers, following from existing research showing a focus on positive role models, or individuals who have overcome similar challenges, to enhance motivation and well-being (Corcoran et al., 2011; Huguet et al, 2001; Lockwood \& Kunda, 1997; Taylor \& Lobel, 1989). In clear support of this hypothesis, the present findings showed upward social comparisons to be by far the most effective self-regulation strategy across all outcomes, and the only comparison strategy to predict lower quitting intentions. More specifically, teachers who reported more upward comparisons were found to experience, not only lower levels of burnout (exhaustion, depersonalization, accomplishment), but also higher job satisfaction and optimal teaching emotions (enjoyment, anger, anxiety), as well as less frequent illness symptoms and thoughts about quitting the profession. These results are consistent with theoretical assertions that teacher self-efficacy can indeed be facilitated through the vicarious experience of observing demonstrations of skillful teaching (Tschannen-Moran et al., 1998; see also Kunter et al., 2011), as well as research in adult and student populations showing comparisons with others who have successfully overcome similar challenges to contribute to positive affect and motivation (e.g., Bailis et al., 1995; Huguet et al., 2001). The present findings thus contribute to research on the potential psychological benefits of upward social comparisons in showing this strategy to most strongly and consistently predict, not only physical and psychological health outcomes in teachers, but also their stated intentions to quit the profession.

\section{Hypothesis 4: Moderation by experience}

Consistent with existing social comparison research showing the effects of upward social comparisons to contribute to well-being particularly for individuals who are struggling to make social connections (e.g., Bailis \& Chipperfield, 2006) or reporting low perceptions of personal control (e.g., Bailis et al, 2005; Buunk et al., 1990), our results also suggested that upward social comparisons were more beneficial for less experienced teachers. More specifically, whereas comparisons with relevant role models were of benefit to more experienced teachers with respect to job satisfaction, intentions to quit, and teaching-related enjoyment, these effects were noticeably stronger for new teachers. These moderation effects underscore the importance of educational research examining motivation and self-regulation early in the teaching profession (e.g., within the first two years; Roness, 2011) as well as continued efforts in social comparison research to examine how individual differences on psychosocial factors might moderate the effects of these comparisons on adjustment (e.g., Buunk et al., 1990; Lockwood et al., 2004).

\section{Limitations and future directions}

Concerning potential limitations of the present study to be addressed in future research, five main issues warrant consideration. First, the study employed a newly developed scale adapted from the Optimization of Primary and Secondary Control measure (OPS; Haase et al., 2008) consisting of only two items per subscale, with the two items for the horizontal comparisons measure not being highly correlated $(r=.33)$. Whereas the first item addressed teachers bonding with others who similarly failed to meet personal teaching goals, the second focused on connecting with other teachers over difficulties with students. Additional analyses further suggest that teachers' attempts to bond over shared personal failures may be primarily responsible for the negative effects of horizontal comparisons, with post-hoc single-item correlations showing the personal failure item to be more strongly correlated with burnout than the student-focused item (e.g. $r=-.12$ vs. -.04 for personal accomplishment).

Accordingly, in addition to the moderate internal reliability estimates found for the upward and downward comparison measures (.63 and .51), further research to develop more in-depth and reliable self-report measures of social comparisons in teachers is needed. Further, selfreport or interview methods inquiring as to variety of specific teaching experiences and the types of social comparisons made by teachers in response would provide a more ecologically valid means of exploring the prevalence and effectiveness of each social comparison strategy. Additionally, given the importance of social comparison processes for responding to not only setbacks but also success experiences in educational settings (e.g., outperforming others, Exline \& Lobel, 1999), future research should explore how teachers compare amongst themselves in response to positive events is recommended (e.g., student successes, teaching recognition). 
The second limitation concerns mediating and moderating variables not investigated in this study. More specifically, as evidenced by prior research showing other psychosocial variables such as self-efficacy, achievement goals, and perceived control to moderate the effects of social comparisons (e.g., Butler, 1992; Buunk et al., 1990; Lockwood et al., 2004), it is possible that similar moderation effects may account for the mixed effects observed (e.g., downward comparisons). Additionally, further examination of the moderating effects of additional variables not explored in this study, such as school culture, cohort effects, leadership style, and personality-related factors, could also help to ascertain how and when these effects occur in real-world teaching contexts. Similarly, it is possible that other, more directly overlapping socio-cognitive variables not assessed in this study may to some extent account for the observed relationships, for example, the negative effects of horizontal comparisons on adjustment outcomes (e.g., competitiveness, belongingness, social goals; Bergin \& Bergin, 2009; Butler, 2012; Van Ryzin et al., 2009). As such, it is anticipated that future research in which additional potential moderators or mediators of the relations between social comparisons and adjustment in teachers are examined may shed more light on the mixed findings in this study.

Third, given that the comparisons examined in this study were from teachers to specific others, future research to investigate comparisons made by teachers with larger reference groups or between teacher cohorts (e.g., two groups of teachers) is also needed for greater insight into the varied ways in which teachers compare themselves on a collective level. Furthermore, to better understand the positive implications of upward comparisons on teacher well-being, further study is recommended to also examine other types of upward comparisons that may not be motivating for teachers. For example, upward comparisons would not be expected to be beneficial for teachers who focus on the disparities between themselves and role models, or for whom the success of the role model is perceived as unattainable. In addition, future studies would benefit from exploring domain specificity in regards to the types of social comparisons preferred by teachers in response to varied classroom stressors (i.e., dealing with setbacks regarding student misbehavior as compared to setbacks regarding interactions with colleagues or administrators).

A fourth limitation pertains to the cross-sectional and self-report nature of the study data. Given that the long-term relationships between these social comparisons strategies and adjustment outcomes may differ from those concurrently observed, future longitudinal research is warranted to replicate these findings over a longer duration (e.g., six-month lag). Likewise, whereas the present methodology consisted exclusively of self-report measures, further examination of teachers' social comparison strategies utilizing more objective methodologies that circumvent self-report biases (e.g., common method variance) is encouraged. For example, experience sampling methods could better inform our understanding of how teachers compare themselves to others in real-life classroom settings (cf. Goetz, Frenzel, Stoeger, \& Hall, 2010), with objective health indicators also serving as more ecologically valid outcome measures (e.g., teacher self-efficacy and cortisol; Schwerdtfeger, Konermann, \& Schonhofen, 2008).

Finally, whereas the present study findings suggest clear potential psychological benefits for teachers who focus on role models, as well as possible negative implications of seeking social comparisons with similar others over shared teaching failures, further research to experimentally evaluate these assertions is needed. More specifically, interventions promoting a focus on role models among teachers, and explicitly discouraging teachers to seek out similarly failing others (e.g., "teaching misery does not love company"), are recommended to more directly evaluate the causal implications of the present findings. For example, teachers could be provided an opportunity to reflect on a teacher they admire as part of a professional development seminar, or dialogue with an experienced teacher who has overcome setbacks, so as to promote adjustment and persistence in new teachers. In sum, it is anticipated that future research on the types of social comparisons made by teachers could help to meaningfully inform the development of first-year orientation and ongoing professional development programs for teachers aimed at both reducing attrition and improving psychological well-being. 


\title{
Funding
}

This study was supported by a doctoral fellowship to the first author and grant funding to the second author from the Social Sciences and Humanities Research Council of Canada (\#8952011-1006), and a grant to the second author from Le Fonds de recherche du Québec Société et culture (\#2013-NP-165885).

\section{Acknowledgement}

The assistance of the Achievement Motivation and Emotion (AME) Research Group in the data collection process is greatly appreciated.

\section{Appendix A}

\author{
Social Comparison Questionnaire Items \\ $1=$ Strongly disagree \\ $2=$ Somewhat disagree \\ $3=$ Neither agree nor disagree \\ 4 = Somewhat agree \\ $5=$ Strongly agree

\section{Downward Social Comparisons}

When I experience teaching setbacks, I remind myself that I am better off than other teachers in many ways.

When dealing with teaching challenges, I remind myself that other teachers have even worse experiences.

\section{Horizontal Social Comparison}

If I don't reach my teaching goals, I will tell myself that many other teachers are in the same situation.

When I have difficulties with my students, I keep in mind that other teachers are struggling too.

\section{Upward Social Comparisons}

When I experience teaching difficulties, I remind myself of successful teachers who overcame similar setbacks.

When faced with teaching challenges, I remind myself of role models who went through similar circumstances. 


\section{References}

Antoniou, A. S., Polychroni, F., \& Vlachakis, A. N. (2006). Gender and age differences in occupational stress and professional burnout between primary and high-school teachers in Greece. Journal of Managerial Psychology, 21(7), 682-690.

Austin, V., Shah, S., \& Muncer, S. (2005). Teacher stress and coping strategies used to reduce stress. Occupational Therapy International, 12(2), 63-80.

Bailis, D. S., Chipperfield, J. G., \& Helgason, T. R. (2008). Collective self-esteem and the onset of chronic conditions and activity reduction in a longitudinal study of aging. Social Science and Medicine, 66, 1817-1827.

Bailis, D. S., Chipperfield, J. G., \& Perry, R. P. (2005). Optimistic social comparisons of older adults low in primary control: A prospective analysis of hospitalization and mortality. Health Psychology, 24(4), 393-401.

Bailis, D. S., \& Chipperfield, J. G. (2006). Emotional and self-evaluative effects of social comparison information in later life: How are they moderated by collective self-esteem? Psychology and Aging, 21, 291-302.

Beckstead, J. W. (2002). Confirmatory factor analysis of the Maslach Burnout Inventory among Florida nurses. International Journal of Nursing Studies, 39(8), 785-792.

Bergin, C., \& Bergin, D. (2009). Attachment in the classroom. Educational Psychology Review, 21(2), 141-170.

Blanton, H, Buunk, B. P., Gibbons, F. X., \& Kuyper, H. (1999). When better-than-others compares upward: The independent effects of comparison choice and comparative evaluation on academic performance. Journal of Personality and Social Psychology, 76, 420-430.

Blase, J. J. (1986). A qualitative analysis of sources of teacher stress: Consequences for performance. American Educational Research Journal, 23(1), 13-40.

Bowlby, J. (1951). Maternal care and mental health (Vol. 2). World Health Organization: Geneva.

Bowlby, J. (2008). Attachment. New York, NY: Basic books.

Butler, R. (1992). What young people want to know when: Effects of mastery and ability goals on interest in different kinds of social comparisons. Journal of Personality and Social Psychology, 62(6), 934-943.

Butler, R. (2007). Teachers' achievement goals and associations with teachers' help-seeking: examination of a novel approach to teacher motivation. Journal of Educational Psychology, 99, 241-252.

Butler, R. (2012). Striving to connect: Extending an achievement goal approach to teacher motivation to include relational goals for teaching. Journal of Educational Psychology, 104(3), 726-742.

Butler, R., \& Shibaz, L. (2008). Achievement goals for teaching as predictors of students' perceptions of instructional practices and students' help seeking and cheating. Learning and Instruction, 18(5), 453-467.

Buunk, B. P., \& Mussweiler, T. (2001). New directions in social comparison research. European Journal of Social Psychology, 31(5), 467-475.

Buunk, B. P., Collins, R. L., Taylor, S. E., VanYperen, N. W., \& Dakof, G. A. (1990). The affective consequences of social comparison: either direction has its ups and downs. Journal of Personality and Social Psychology, 59(6), 1238-1249.

Byrne, B. M. (1994). Burnout: Testing for the validity, replication, and invariance of causal structure across elementary, intermediate, and secondary teachers. American Educational Research Journal, 31(3), 645-673.

Chipperfield, J. G., \& Perry, R. P. (2006). Primary-and secondary-control strategies in later life: Predicting hospital outcomes in men and women. Health Psychology, 25(2), 226-236.

Cohen, S., \& Hoberman, H. M. (1983). Positive events and social supports as buffers of life change stress. Journal of Applied Social Psychology, 13(2), 99-125.

Cohen, S., \& McKay, G. (1984). Social support, stress and the buffering hypothesis: A theoretical analysis. Handbook of Psychology and Health, 4, 253-267. 
Collins, R. L. (1996). For better or worse: The impact of upward social comparison on selfevaluations. Psychological Bulletin, 119(1), 51-69.

Corcoran, K., Crusius, J., \& Mussweiler, T. (2011). Social comparison: Motives, standards, and mechanisms. In D. Chadee (Ed.), Theories in Social Psychology (pp. 119-139). Oxford, UK: WileyBlackwell.

Crocker, J., Luhtanen, R., Blaine, B., \& Broadnax, S. (1994). Collective self-esteem and psychological well-being among White, Black, and Asian college students. Personality and Social Psychology Bulletin, 20(5), 503-513.

Exline, J., \& Lobel, M. (1999). The perils of out performance: Sensitivity about being the target of a threatening upward comparison. Psychological Bulletin, 125, 307-337.

Festinger, L. (1954). A theory of social comparison processes. Human Relations, 7(2), 117-140.

Freeman, T. M., Anderman, L. H., \& Jensen, J. M. (2007). Sense of belonging in college freshmen at the classroom and campus levels. The Journal of Experimental Education, 75(3), 203-220.

Frenzel, A. C., Goetz, T., Stephens, E. J., \& Jacob, B. (2009) Antecedents and effects of teachers' emotional experiences: An integrated perspective and empirical test. In P.A. Schutz \& M. Zemblays (Eds), Advances in teacher emotion research (pp.129-151). Dordrecht: Springer.

Friedman, I. A., \& Farber, B. A. (1992). Professional self-concept as a predictor of teacher burnout. The Journal of Educational Research, 86(1), 28-35.

Fédération canadienne des enseignanteset et des enseignants. (2004). Recrutement et maintien du personnel enseignant: Pourquoi les enseignants et enseignantes entrent dans la profession, y restent ou la quittent. Bulletin des Services Économiques et Services aux Membres, 5, 1-20.

Furrer, C., \& Skinner, E. (2003). Sense of relatedness as a factor in children's academic engagement and performance. Journal of Educational Psychology, 95(1), 148-162.

George, D., \& Mallery, P. (2003). SPSS for Windows step by step: A simple guide and reference. 11.0 update (4thEd.), Boston: Allyn \& Bacon.

Goddard, R. D., Hoy, W. K., \& Hoy, A. W. (2000). Collective teacher efficacy: Its meaning, measure, and impact on student achievement. American Educational Research Journal, 37(2), 479-507.

Goetz, T., Frenzel, A. C., Stoeger, H., \& Hall, N. C. (2010). Antecedents of everyday positive emotions: An experience sampling analysis. Motivation and Emotion, 34, 49-62.

Goodenow, T. (1993). Classroom belonging among early adolescent students: Relationships to Motivation and Achievement. Journal of Early Adolescence, 13(1), 21-43.

Greenglass, E. R., \& Burke, R. J. (1988). Work and family precursors of burnout in teachers: Sex differences. Sex Roles, 18(3-4), 215-229.

Griffith, J., Steptoe, A., \& Cropley, M. (1999). An investigation of coping strategies associated with job stress in teachers. British Journal of Educational Psychology, 69(4), 517-531.

Haase, C. M., Heckhausen, J., \& Koeller, O. (2008). Goal engagement in the school-to-work transition: Beneficial for all, particularly for girls. Journal of Research on Adolescence, 18, 671-698.

Hackett, R. D., Lapierre, L. M., \& Hausdorf, P. A. (2001). Understanding the links between work commitment constructs. Journal of Vocational Behavior, 58, 392-413.

Hakmiller, K. L. (1966). Threat as a determinant of downward comparison. Journal of Experimental Social Psychology, 1, 32-39.

Hall, N. C. (2008). Self-regulation of primary and secondary control in achievement settings: A process model. Journal of Social and Clinical Psychology, 27(10), 1126-1164.

Hall, N. C., Chipperfield, J. G., Heckhausen, J., \& Perry, R. P. (2010). Control striving in older adults with serious health problems: A 9-year longitudinal study of survival, health, and well-being. Psychology and Aging, 25(2), 432-445.

Hall, N. C., Chipperfield, J. G., Perry, R. P., Ruthig, J. C., \& Goetz, T. (2006). Primary and secondary control in academic development: Gender-specific implications for stress and health in college students. Anxiety, Stress, and Coping, 19, 189-210.

Hall, N. C., Perry, R. P., Ruthig, J. C., Hladkyj, S., \& Chipperfield, J. G. (2006). Primary and secondary control in achievement settings: A longitudinal field study of academic motivation, 
emotions, and performance. Journal of Applied Social Psychology, 36, 1430-1470.

Heckhausen, J. (1999). Developmental regulation in adulthood: Age-normative and sociostructural constraints as adaptive challenges. Cambridge, U.K.: Cambridge University Press.

Heckhausen, J., \& Schulz, R. (1995). A life-span theory of control. Psychological Review, 102, 284-304.

Heckhausen, J., Wrosch, C., \& Schulz, R. (2010). A motivational theory of life-span development. Psychological Review, 117(1), 36-60.

Heckhausen J, Schulz R, Wrosch C. (1998). Developmental regulation in adulthood: Optimization in primary and secondary control-A multiscale questionnaire. Berlin, Germany: Max Planck Institute for Human Development.

Holton, G. (2004). Robert K. Merton, 4 July 1910 - 23 February 2003, American Philosophical Society, 148, 505-517.

Houlfort, N., \& Sauvé, F. (2010). La santé psychologique des enseignants de la Fédération autonome de l'enseignement. [Psychological health of teachers belonging to Fédération autonome de l'enseignement]. Montreal: École nationale d'administration publique.

Huguet, P., Dumas, F., Monteil, J. M., \& Genestoux, N. (2001). Social comparison choices in the classroom: Further evidence for students' upward comparison tendency and its beneficial impact on performance. European Journal of Social Psychology, 31(5), 557-578.

Ingersoll, R. M. (2003). Is there really a teacher shortage? Washington, DC: Center for the Study of Teaching and Policy.

Jagacinski, C. M., \& Nicholls, J. G. (1987). Competence and affect in task involvement and ego involvement: The impact of social comparison information. Journal of Educational Psychology, 79(2), 107-114.

Karsenti, T., \& Collin, S. (2013). Why are new teachers leaving the profession? Results of a Canada-wide survey. Education, 3(3), 141-149.

Kemmelmeier, M., \& Oyserman, D. (2001). Gendered influence of downward social comparisons on current and possible selves. Journal of Social Issues, 57, 129-148.

Kitchel, T., Smith, A. R., Henry, A. L., Robinson, J. S., Lawver, R. G., Park, T. D., \& Schell, A. (2012). Teacher job satisfaction and burnout viewed through social comparisons. Journal of Agricultural Education, 53(1), 31-44.

Klassen, R. M., \& Chiu, M. M. (2011). The occupational commitment and intention to quit of practicing and pre-service teachers: Influence of self-efficacy, job stress, and teaching context. Contemporary Educational Psychology, 36(2), 114-129.

Klassen, R. M., Tze, V. M., Betts, S. M., \& Gordon, K. A. (2011). Teacher efficacy research 1998-2009: Signs of progress or unfulfilled promise? Educational Psychology Review, 23(1), $21-43$.

Klassen, R. M., Perry, N. E., \& Frenzel, A. C. (2012). Teachers' relatedness with students: An underemphasized component of teachers' basic psychological needs. Journal of Educational Psychology, 104(1), 150-165.

Kokkinos, C. M. (2007). Job stressors, personality and burnout in primary school teachers. British Journal of Educational Psychology, 77(1), 229-243.

Kuhl, J. (1996). Who controls whom when "I control myself"? Psychological Inquiry, 7, 61-68.

Kunter, M., Frenzel, A., Nagy, G., Baumert, J., \& Pekrun, R. (2011). Teacher enthusiasm: Dimensionality and context specificity. Contemporary Educational Psychology, 36(4), 289-301.

Kyriacou, C., \& Kunc, R. (2007). Beginning teachers' expectations of teaching. Teaching and TeacherEducation, 23(8), 1246-1257.

Lazarus, R. S., \& Folkman, S. (1984). Coping and adaptation. In W.D. Gentry (Ed.), The handbook of hehavioral medicine (pp. 282-325). New York, NY: Guilford.

Locke, K. D. (2003). Status and solidarity in social comparison: Agentic and communal values and vertical and horizontal directions. Journal of Personality and Social Psychology, 84(3), 619-631.

Locke, K. D. (2005). Connecting the horizontal dimension of social comparison with self-worth and self-confidence. Personality and Social Psychology Bulletin, 31(6), 795-803. 
Lockwood, P., Dolderman, D., Sadler, P., \& Gerchak, E. (2004). Feeling better about doing worse: Social comparisons within romantic relationships. Journal of Personality and Social Psychology, 87(1), 80-95.

Lockwood, P., Jordan, C. H., \& Kunda, Z. (2002). Motivation by positive or negative role models: Regulatory focus determines who will best inspire us. Journal of Personality and Social Psychology, 83(4), 854-864.

Lockwood, P., \& Kunda, Z. (1997). Superstars and me: Predicting the impact of role models on the self. Journal of Personality and Social Psychology, 73(1), 91-103.

Lyubomirsky, S., \& Ross, L. (1997). Hedonic consequences of social comparison: A contrast of happy and unhappy people. Journal of Personality and Social Psychology, 73(6), 1141-1157.

Maslach, C., Jackson, S. E., \& Leiter, M. P. (1996). Maslach burnout inventory manual (3rd ed.). Mountain View, California: CPP, Inc.

Manassero, M. A., Garcia Buades, E., Torrens, G., Ramis, C., Vázquez, A., \& Ferrer, V. A. (2006). Teachers burnout: Attributional aspects. Psychology in Spain, 10(1), 66-74.

McCormick, J. (1997). Occupational stress of teachers: Biographical differences in a large school system. Journal of Educational Administration, 35(1), 18-38.

McCormick, J., \& Shi, G. (1999). Teachers' attributions of responsibility for their occupational stress in the People's Republic of China and Australia. British Journal of Educational Psychology, 69(3), 393-407.

Meyers, L. S., Gamst, G., \& Guarino, A. J. (2006). Applied multivariate research: Design and interpretation. Sage.

Moe, A., Pazzaglia, F., \& Ronconi, L. (2010). When being able is not enough: The combined value of positive affect and self-efficacy for job satisfaction in teaching. Teaching and Teacher Education, $26,1145-1153$.

Murray, H. (1938). Explorations in personality. New York, NY: Oxford University Press,

Niemiec, C. P., \& Ryan, R. M. (2009). Autonomy, competence, and relatedness in the classroom: Applying self-determination theory to educational practice. Theory and Research in Education, $7(2), 133-144$.

Oettingen, G., \& Gollwitzer, P. M. (2009). Making goal pursuit effective: Expectancy-dependent goal setting and planned goal striving. In J. P. Forgas, R. F. Baumeister, D. F. Tice (Eds.), Psychology of Self-Regulation: Cognitive, Affective, and Motivational Processes (pp. 127-146). New York, NY: Psychology Press.

Pas, E. T., Bradshaw, C. P., \& Hershfeldt, P. A. (2012). Teacher-and school-level predictors of teacher efficacy and burnout: Identifying potential areas for support. Journal of School Psychology, $50(1), 129-145$.

Parker, K., Hannah, E., \& Topping, K. J. (2006). Collective teacher efficacy, pupil attainment and socio-economic status in primary school. Improving Schools, 9(2), 111-129.

Pintrich, P. R. (1999). Taking control of research on volitional control: Challenges for future theory and research. Learning and Individual Differences, 11, 335-354.

Pohlmann, B., \& Möller, J. (2009). On the benefit of dimensional comparisons. Journal of Educational Psychology, 101(1), 248.

Pyszczynski, T., Greenberg, J., \& LaPrelle, J. (1985). Social comparison after success and failure: Biased search for information consistent with a self-serving conclusion. Journal of Experimental Social Psychology, 21(2), 195-211.

Roness, D. (2011). Still motivated? The motivation for teaching during the second year in the profession. Teaching and TeacherEducation, 27(3), 628-638.

Roth, R. R., \& Gold, Y. (2003). Teachers managing stress and preventing burnout. New York, NY: Taylor \& Francis.

Ryan, R. M., \& Deci, E. L. (2000). Self-determination theory and the facilitation of intrinsic motivation, social development, and well-being. American Psychologist, 55(1), 68-78.

Schwerdtfeger, A., Konermann, L., \& Schonhofen, K. (2008). Self-efficacy as a health-protective resource in teachers? A biopsychological approach. Health Psychology, 27, 358-368. 
Sheeran, P., Abrams, D., \& Orbell, S. (1995). Unemployment, self-esteem, and depression: A social comparison theory approach. Basic and Applied Social Psychology, 17(1-2), 65-82.

Skaalvik, E. M., \& Skaalvik, S. (2011). Teacher job satisfaction and motivation to leave the teaching profession: Relations with school context, feeling of belonging, and emotional exhaustion. Teaching and TeacherEducation, 27(6), 1029-1038.

Skinner, E. A., Edge, K., Altman, J., \& Sherwood, H. (2003). Searching for the structure of coping: A review and critique of category systems for classifying ways of coping. Psychological Bulletin, 129, 216-269.

Smith, R. H. (2000). Assimilative and contrastive emotional reactions to upward and downward social comparisons. Handbook of social comparison: Theory and research (pp. 173-200). New York: Plenum.

Stapel, D. A., \& Koomen, W. (2001). I, we, and the effects of others on me: how self-construal level moderates social comparison effects. Journal of Personality and Social Psychology, 80(5), 766-781.

Stewart, T. L., Chipperfield, J. G., Perry, R. P., \& Weiner, B. (2012). Attributing illness to 'old age:' Consequences of a self-directed stereotype for health and mortality. Psychology \& Health, 27(8), 881-897.

Stewart, T. L., Chipperfield, J. G., Ruthig, J. C., \& Heckhausen, J. (2013). Downward social comparison and subjective well-being in late life: The moderating role of perceived control. Aging and Mental Health, 17(3), 375-385.

Suls, J., Martin, R., \& Wheeler, L. (2002). Social comparison: Why, with whom, and with what effect? Current Directions in Psychological Science, 11(5), 159-163.

Suls, J. E., \& Wheeler, L. E. (2000). Handbook of social comparison: Theory and research. New York: KluwerAcademic/Plenum.

Sutton, R. E. (2004). Emotional regulation goals and strategies of teachers. Social Psychology of Education, 7(4), 379-398.

Taylor, S. E., \& Lobel, M. (1989). Social comparison activity under threat: downward evaluation and upward contacts. Psychological Review, 96(4), 569-575.

Tesser, A. (1988). Toward a self-evaluation maintenance model of social behavior. Advances in Experimental Social Psychology, 21, 181-227.

Tschannen-Moran, M., Hoy, A. W., \& Hoy, W. K. (1998). Teacher efficacy: Its meaning and measure. Review of Educational Research, 68(2), 202-248.

Totterdell, P., \& Parkinson, B. (1999). Use and effectiveness of self-regulation strategies for improving mood in a group of trainee teachers. Journal of Occupational Health Psychology, 4(3), 219-232.

Van Ryzin, M. J., Gravely, A. A., \& Roseth, C. J. (2009). Autonomy, belongingness, and engagement in school as contributors to adolescent psychological well-being. Journal of Youth and Adolescence, 38(1), 1-12.

Watt, H. M., \& Richardson, P. W. (2007). Motivational factors influencing teaching as a career choice: Development and validation of the FIT-Choice scale. The Journal of Experimental Education, 75(3), 167-202.

Wigfield, A., Tonks, S., \& Klauda, S. L. (2009). Expectancy-value theory. In K. R. Wentzel \& A. Wigfield (Eds.), Handbook of motivation at school (pp. 55-76). Mahwah, NJ: Lawrence Erlbaum Associates.

Wang, H., Hall, N. C., \& Rahimi, S. (2015). Self-efficacy and causal attributions in teachers: Effects on burnout, job satisfaction, illness, and quitting intentions. Teaching and Teacher Education, 47, 120-130.

Wills, T. A. (1981). Downward comparison principles in social psychology. Psychological Bulletin, 90(2), 245-271.

Wheeler, L., \& Miyake, K. (1992). Social comparison in everyday life. Journal of Personality and Social Psychology, 62(5), 760-773.

White, J. B., Langer, E. J., Yariv, L., \& Welch IV, J. C. (2006). Frequent social comparisons and destructive emotions and behaviors: The dark side of social comparisons. Journal of Adult Development, 13(1), 36-44. 
Wood, J. V. (1989). Theory and research concerning social comparisons of personal attributes. Psychological Bulletin, 106(2), 231-248.

Wolters, C. A. (2003). Regulation of motivation: Evaluating an under emphasized aspect of selfregulated learning. Educational Psychologist, 38(4), 189-205.

Yong, Z., \& Yue, Y. (2007). Causes for burnout among secondary and elementary school teachers and preventive strategies. Chinese Education \& Society, 40(5), 78-85.

Zhang, Q., \& Zhu, W. (2007). Teacher stress, burnout, and social support in Chinese secondary education. Human Communication, 10(4), 487-496. 